\title{
CRESPOS: O CABELO COMO ÍCONE DA IDENTIDADE NEGRA. MEMÓRIA E ESTÉTICA, A CIRCULAÇÃO DE IDEIAS E VALORES NA REALIDADE BRASILEIRA ${ }^{1}$
}

Neli Gomes da Rocha ${ }^{2}$

- Enviado em 27/01/2016

- Aprovado em 21/02/2016

O corpo é, por excelência, informante e transmissor de ideias e valores, experiências e narrativas envoltas de subjetividades que expressam "um lugar" de fala. Na vida moderna, esse processo se atualiza e passa a dialogar com modalidades de "domesticação" e "padronização" da "boa aparência" e impregnam imaginários que ecoam no cotidiano social, como isso, o mercado de bens e serviços 'cria' as condições para os indivíduos alcançarem o desejo que lhes foi inculcado, e se tornar algo amplamente acessível a partir da chegada de miraculosas e inovadoras técnicas de manipulação dos fios e pele, todavia, sem atentar para os cuidados com a saúde física e mental de quem adere aos procedimentos.

Manipular os fios crespos tornando-os lisos, são procedimentos tradicionais que historicamente tendem a alterar provisoriamente o formato natural do fio crespo com propostas de transformação que solucionem os percalços cotidianos, atuando na textura e na vitalidade. Com isso, os indivíduos gradualmente aderem, tornando-o portador de traços físicos mais 'aceitáveis', inicialmente aos padrões das elites, e posteriormente aos aspirantes a ela (elite), especialmente após as décadas de 1920 e 1930 no Brasil. A proposta da pesquisa é refletir sobre as estratégias dos

\footnotetext{
1 Pesquisa de doutorado em andamento sob a orientação da Professora Doutora Maria Tarcisa da Silva Bega no Programa de Pós-graduação em Sociologia da UFPR. Co-orientação do Professor Doutor José Miguel Rasia durante o ano de 2015.

2 Doutoranda do Programa de Pós-Graduação em Sociologia Universidade Federal do Paraná/BRASIL. Graduada em Ciências Sociais pela UFPR (primeira turma de cotistas raciais); Mestre em Sociologia pela UFPR; Cursa Doutorado em Sociologia UFPR; membro do grupo de pesquisa Pensamento social, intelectuais e circulação de ideias, na linha de Pensamento social e rotinização das ideias; Atua como pesquisadora na área das Relações Raciais no Brasil; Integra o Núcleo de Estudos Afro brasileiros da UFPR. Contato: neliproducao@yahoo.com.br.
} 
agentes diante da valorização de padrão estético exógeno à realidade brasileira identificado como processo de "branqueamento", a exemplo da manipulação do cabelo crespo e dos traços físicos, como a cor da pele e formato de nariz, do indivíduo negro na busca por "aceitação" e mobilidade social, como apontam estudos de COUTINHO (2005); FIGUEIREDO (2010), entre outros.

Algumas questões pairam no exercício reflexivo da pesquisa:

1. Quais técnicas de manipulação e cuidados com os fios crespos em contextos anteriores ao processo colonial? Por exemplo, a prática dos trançados capilares e adornos, como turbantes, no processo de transmissão de conhecimento, utilizando a oralidade como principal transmissora de saberes.

Participante de uma 'configuração histórica' a arte capilar das tranças e a elaboração de complexos adornos com tecidos é entendida aqui como o domínio técnico de um saber geracional, predominantemente matrilinear e de significativa expressão cultural de matriz africana, disseminada pelas grandes migrações ocorridas entre a África e as Américas, configuram elementos simbólicos que são ecos da memória compartilhada da Diáspora africana, assim como apontam os estudos sobre a temática, "as culturas do Atlântico Negro criaram veículos de consolação através da mediação do sofrimento. Elas especificaram formas estéticas e contra-estéticas e uma distinta dramaturgia da recordação que caracteristicamente separam a genealogia, da geografia, e o ato de lidar com o de pertencer. (GILROY, 2001, p.13)

Para tanto, é salutar a figura da agente mobilizadora, "a trançadeira" a pessoa que domina a técnica de manipulação dos crespos tanto em contexto pré-colonial, quanto na formação do "Novo Mundo" nas Américas. E nos revela uma continuidade por meio das 'mãos de sabedoria' e remete ao que foi vivido por grupos culturais ancestrais e o processo de ressignificação ao 'mexer' na cabeça se ativa a 'memória ancestral' materializada nos trançados capilares de formatos variados. Em consonância com "o dinâmico trabalho de memória que é estabelecido e moralizado na edificação da intercultura da diáspora construiu a coletividade e legou tanto uma política como uma hermenêutica aos membros contemporâneos." (GILROY, 2001, p.13)

Realocados além-mar, grupos descendentes de africanos reaprendem e adaptam os cuidados com o corpo e os cabelos. Ao manusear os fios crespos, as trançadeiras atuam como transmissoras da 'memória ancestral' no exercício de repensar o mundo, dinâmico e diferenciado daquele descrito pelos valores culturais e estéticos do ocidente, herdado pelo mundo moderno. As 'guardiãs das memórias' de matrizes africanas, as "trançadeiras" tecem comportamentos sociais e trançam ideias, 
possibilitando repensar o mundo de modo diferenciado do qual o ocidente colonialista nos legou. E assim, adentramos então, para uma "dimensão simbólica da oralidade na realidade brasileira como elemento da diáspora africana, o conhecimento produzido pela oralidade não se estabelece num lugar para dele fazer sua morada, em vez disso se aprofunda no seio de todo lugar, alguma coisa como não-lugar (u-topos) abrindo à experiência” (Antonacci apud Bidima, 2013, p.23).

2. Na vida moderna esse processo de cuidados com os corpos se atualiza e passa a conviver com outras modalidades de "domesticação" e "padronização", todavia, sem atentar para os cuidados com a saúde física e mental de quem adere aos procedimentos.

3. O contato com outras perspectivas epistemológicas permitiu a ampliação do campo de pesquisa, a exemplo de produções Pós-coloniais, visando compreender maneiras com as quais as sociedades de matrizes africanas se comunicam e expressam suas visões de mundo por meio da corporeidade.

No caso da realidade brasileira, nos interessa perceber os usos e sentidos dos cabelos crespos e as relações de convício social tanto na esfera da intimidade, quanto no âmbito das relações pessoais e profissionais. Sem perder de vista a complexidade ainda vigente das relações raciais no Brasil na relação entre "padrões estéticos", "identidades" e "práticas sociais" na perspectiva da emancipação estético-corporal e cultural.

\section{MÉTODO}

A partir da memória social dos agentes participantes poderemos averiguar as ações de recordação social da experiência vivida na relação com a própria corporeidade, assim como identificar possibilidades de transmissão do conhecimento pela oralidade é aqui considerada como algo complexo e que não se reduz à narrativa verbal, mas perpassa o gestual e o corpórea o que nos coloca entre a crença na superação da rede semântica dos estereótipos e o risco constante do risível, o corpo permanece no lugar onde infinitas apostas continuarão a se realizar. Pensar o corpo como matéria ou pensá-lo como virtual são apenas alguns dos desafios contemporâneos diante dos quais a estratégia mais adequada parece ser o jogo, a abertura, a aposta no risco, a experimentação, a composição que integre a alteridade e a semelhança com o outro e com o mundo. 
A memória social torna os cabelos crespos um elemento mnemônico, o "fio condutor" da pesquisa é uma base de comunicação que remete às práticas sociais cotidianas e suas origens no continente africano, "memórias ancoradas em experiências dos que só têm no corpo suas formas de comunicação, heranças em performances" (ANTONACCI, 2013, p.13).

A corporeidade humana incorpora e reflete concepções subjetivas consideradas como "Ecologias de pertencimento" (GILROY, 2001) e configura um 'modo de saber' e um "modo de fazer' complexo, fruto da oralidade na relação de interação geracional (MANNHEIM). Sendo assim, "corpos de tradições orais são feitos ao longo de gerações, pois 'a presteza de execução que lhes é própria implica uma automatização que a seu turno implica uma tradição longa." (ANTONACI apud ZUMTHOR, 2013, p.24).

Está sendo aplicada a observação participante enquanto prática de pesquisa dirigida na "PERSPECTIVA ETNOMETODOLÓGICA", ou seja, aquela que visa descrever e compreender como, concretamente, os atores sociais atribuem um sentido às suas ações. Para Nasser (2012) a observação "acontece mais entre indivíduos tendo estatutos sociais e culturais heterogêneos, entre membros de classes ou de culturas diferentes." (NASSER, 2012, p. 65).

O material empírico está sendo obtido a partir de atividades formativas no formato de oficina/palestras/minicursos, realizadas em 2015 para grupos heterogêneos: 1. Educadores (professores, gestores, pedagogos, pais, estagiários de sociologia do projeto PIBID); 2. Educandos de diversos níveis de ensino, desde o Ens. Fundamental, Ens. Médio, Ens. Superior Graduação e Especialização) de instituições públicas e privadas em diferentes regiões do Brasil; 3. Ativistas e/ou Militantes do movimento negro de Curitiba e região.

\section{DADOS PRELIMINARES}

A partir da observação participante e de entrevistas não estruturadas já é possível apontar:

1. Para a construção de imaginários sociais em torno da corporeidade negra aqui denominada como "Estética Negra", com o predomínio de estereotipia amplamente disseminada no espaço privado e público, todavia na dimensão do "não-dito". Seja nos espaços educacionais como as escolas, públicas e privadas, seja em estabelecimentos empresariais ou ainda nos sentidos dado pelos meios 
de comunicação nota-se que pessoas com o perfil: cabelo crespo e pele escura são percebidas como distantes da ideia de "boa aparência".

2. A crescente tomada de consciência dos atores na relação com a própria corporeidade negra a partir do contato com outras possibilidades de visões e condutas, rompendo gradualmente com a normativa social na adequação que outrora o agente recorreria diante das repetidas "brincadeiras" depreciativas envolvendo sua corporeidade a exemplo da ideia de "cabelo de bombril", "cabelo duro", "palha de aço" gerando desmotivação e baixa estima, afetando inclusive a continuidade do agente na vida escolar e profissional. É possível dizer que parte da evasão escolar brasileira é motivada por pressões simbólicas usualmente identificadas como bulling.

\section{REFERÊNCIAS}

ANTONACCI, Maria Antonieta (2013). Memórias ancoradas em corpos negros. SP: Educ.

COUTINHO, C.L R. (2005). Estética Negra: o jornal como fonte de pesquisa, Programa de PósGraduação em História regional e local, Universidade do Estado da Bahia. Retirado em: 09 ago. 2010, do site: <http://www.alb.com.br>.

FIGUEIREDO, Ângela (2010). Classe média negra: trajetórias e perfis. Salvador. EDUFBA.

GILROY, Paul. (2001). O Atlântico negro: modernidade e dupla consciência. São Paulo: Editora 34; Rio de janeiro: Universidade Cândido Mendes, Centro de estudos Afro-asiáticos.

NASSER, A.C. Arantes (2012). A pesquisa qualitativa. Enfoques epistemológico e metodológicos. Petropolis/RJ, 3. Ed., Vozes.

\section{LEVANTAMENTO BIBLIOGRÁFICO}

BAUMAN Zigmunt e MAY, Tim (2010). Aprendendo a pensar com a sociologia. RJ: Jorge Zahar Ed., pp. 25 e 25.

BEGA, Maria Tarcisa (2013). Letras e Política no Paraná - Simbolistas e anticlericais na república velha. Curitiba: Editora UFPR. 
DIOUF, Sylviane (2004). As tranças de Bintou. SP: Cosac \& Naif.

MACDONALD, Fiona. (1996), EGÍPCIOS ANTIGOS (Coleção Desafios) São Paulo: Moderna.

FERNANDES, Florestan (2008). A Integração do Negro na Sociedade de Classes. SP: Globo. (2007). O negro no mundo dos brancos. SP: Globo.

FLORES, M.B.R. (2007). Tecnologia e estética do racismo: ciência e arte na política da beleza. Chapecó: Argos.

FREYRE, Gilberto (1986). Casa-grande \& senzala: formação da família brasileira sob o regime da economia patriarcal, SP: Círculo do Livro.

(1969). Novo mundo nos trópicos. SP: Nacional/EDUSP.

(1990). Sobrados e mucambos. RJ: Record.

GOMES, Nilma L. (2008), Sem perder a raiz - Corpo e Cabelo como símbolo de identidade negra. 2. ${ }^{\text {a }}$ ed.. Belo Horizonte: Autêntica.

Betina. Belo Horizonte: Mazza Edições, 2009.

LODY, R.G.M. (2004). Cabelos de axé: identidade e resistência. Rio de Janeiro: Senac Nacional.

LOPES, Nei. (2004). Enciclopédia Brasileira da Diáspora Africana. São Paulo: Selo Negro, p. 236-237.

MANNHEIM, Karl. (1982), A sociologia (Coleção Grandes Cientistas Sociais) Mannheim, In: FORACCHI, Marialice Mencarini (Org.) São Paulo: Ática.

NASCIMENTO, Gisêlda Melo. (2006), Feitio de viver:memórias de descendentes de escravos. Londrina: Eduel.

Publicações online: ROCHA, N.G. \& BARBOSA, W. (2014). Ori-oficinas de tranças: reflexão sobre práticas pedagógicas e circulação de ideias na diáspora africana, trabalho apresentado no $8^{\circ}$ Congresso Brasileiro de Pesquisadores (as) Negros(as), Belém-PA. Retirado em: 21 de ago. de 2014, do site:<http://www.copene.org/conteudo/view >.

\section{Artigos em Coletâneas}

BENTO, M.A.S. (2002). Branqueamento e Branquitude no Brasil, Em: I., Carone \& M.A.S. Bento (Orgs.). Psicologia social do racismo: estudos sobre branquitude e branqueamento no Brasil, (pp. 25-58), Petrópolis: Vozes. 
CRESWELL, J. W. (2007), Projeto de pesquisa: métodos qualitativo, quantitativo e misto,(Luciana de Oliveira da Rocha, trad.), Porto Alegre: Artmed.

GOMES, Nilma Lino (2002). Trajetórias escolares, corpo negro e cabelo crespo: reprodução de estereótipos ou ressignificação cultural? Revista Brasileira de Educação, Campinas, n.21, p.40-51, set/out/nov./dez.

CRUZ, t.p. (2013), Os cabelos mágicos: identidade e consumo de mulheres afrodescendentes no instituto beleza natural. (dissertação de mestrado). UFBA.

FIGUEIREDO, Ângela (1994). Beleza pura: símbolos e economia ao redor do cabelo do negro. Monografia para a conclusão do curso de Ciências Sociais. 53 folhas. Faculdade de Filosofia e Ciências Humanas. Universidade Federal da Bahia,Salvador. 